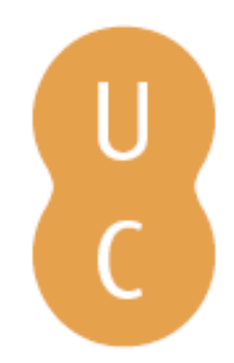

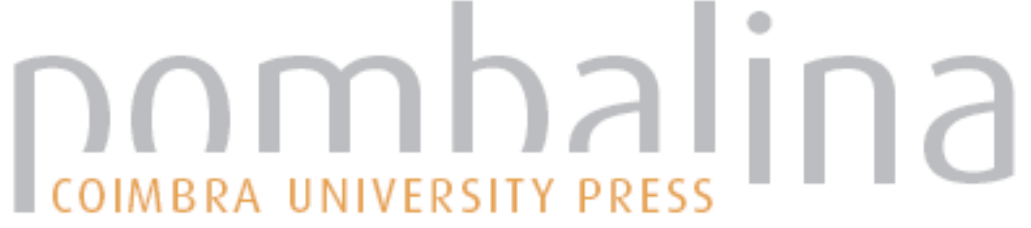

\section{António José de Almeida, a República e a Itália}

Autor(es): $\quad$ Torgal, Luís Reis

Publicado por: Imprensa da Universidade de Coimbra

URL

persistente: URI:http://hdl.handle.net/10316.2/31154

DOI: $\quad$ DOI:http://dx.doi.org/10.14195/978-989-26-0497-8_18

Accessed : $\quad$ 26-Apr-2023 15:02:10

A navegação consulta e descarregamento dos títulos inseridos nas Bibliotecas Digitais UC Digitalis, UC Pombalina e UC Impactum, pressupõem a aceitação plena e sem reservas dos Termos e Condições de Uso destas Bibliotecas Digitais, disponíveis em https://digitalis.uc.pt/pt-pt/termos.

Conforme exposto nos referidos Termos e Condições de Uso, o descarregamento de títulos de acesso restrito requer uma licença válida de autorização devendo o utilizador aceder ao(s) documento(s) a partir de um endereço de IP da instituição detentora da supramencionada licença.

Ao utilizador é apenas permitido o descarregamento para uso pessoal, pelo que o emprego do(s) título(s) descarregado(s) para outro fim, designadamente comercial, carece de autorização do respetivo autor ou editor da obra.

Na medida em que todas as obras da UC Digitalis se encontram protegidas pelo Código do Direito de Autor e Direitos Conexos e demais legislação aplicável, toda a cópia, parcial ou total, deste documento, nos casos em que é legalmente admitida, deverá conter ou fazer-se acompanhar por este aviso.

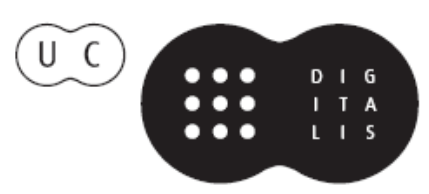


Armando Malheiro da Silva

Maria Luiza Tucci Carneiro

Stefano Salmi

Coordenação

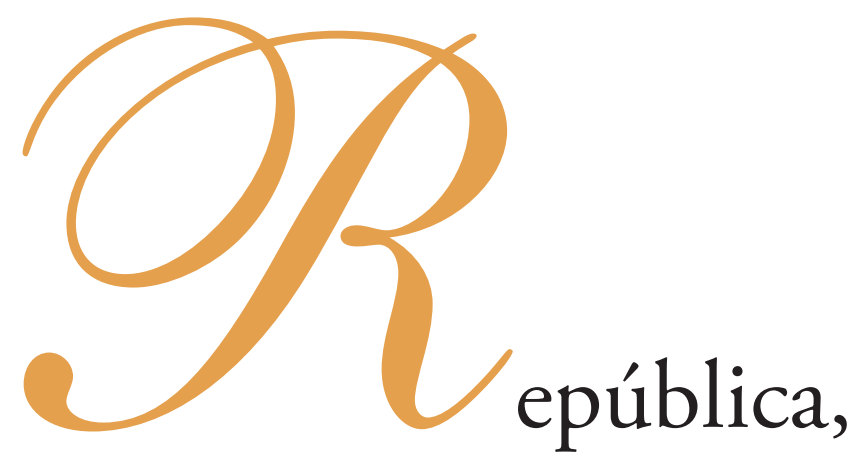

Republicanismo

e Republicanos

Brasil • Portugal • Itália 


\section{Luís Reis Torgal}

\section{ANTÓNIO JOSÉ DE ALMEIDA, A REPÚBLICA E A ITÁLIA}

António José de Almeida, um republicano popular e populista

António José de Almeida (1866-1929) é normalmente considerado um dos combatentes mais significativos do republicanismo português ${ }^{676}$.

Nascido de uma família rural — mas com algum significado político no seio da Monarquia - e num concelho rural, Penacova, a cerca de 25 quilómetros de Coimbra, António José frequentou Medicina na única Universidade então existente no país, ficando célebre pela sua militância republicana, no seio do movimento nacionalista contra o Ultimatum inglês (11 de Janeiro de 1890), que, no contexto da aprovação da "política de ocupação" na Conferência de Berlim, ameaçava Portugal se não abandonasse as sua pretensões de ocupar o espaço geográfico situado entre Angola e Moçambique. Por isso a geração de António José foi denominada a "geração do Ultimatum", afinal a geração que passou da teoria republicana à prática militante e revolucionária. Aliás, em 1891 Almeida publicou no "número-programa" (de 23 de Março) do jornal académico denominado precisamente Ultimatum um dos textos mais polémicos que se escreveu contra a

\footnotetext{
${ }^{676}$ Este artigo tem como base as investigações realizadas para o livro que publicámos, com a colaboração de RAMIRES, Alexandre - António José de Almeida e a República. Discurso de uma vida ou vida de um discurso. Lisboa: Círculo de Leitores, 2004 (nova edição: Lisboa, Temas e Debates, 2005). Ver também a obra de síntese, em colaboração com RAMIRES, Alexandre - António José de Almeida. Fotobiografia. Lisboa: Museu da Presidência da República, 2006. Nesta medida, só em casos especiais citaremos as fontes, que devem ser procuradas nas obras referidas.
} 
Monarquia, artigo esse que tinha como título Bragança, o Último, no qual previa, com uma linguagem sarcástica e polémica, que o rei D. Carlos seria o último monarca da dinastia de Bragança a governar Portugal. A sua prisão por três meses, pena que lhe foi aplicada no processo derivado desta actividade jornalística, iniciou a onda de popularidade no seio dos republicanos, não só em Coimbra como em Lisboa e no Porto, onde sempre se decidiam os passos da política portuguesa.

No início de 1891 vemos António José de Almeida a colaborar, a partir de Coimbra, no movimento estudantil que iria apoiar a primeira revolução republicana que estalou em 31 de Janeiro no Porto, mas sem qualquer sucesso, tornando-se, no entanto, a data um dos "dias simbólicos" do calendário republicano. Mas, o estudante de Medicina tornou-se também um lutador nos meios universitários, tecendo duras críticas à faculdade que frequentou e a muitos dos seus mestres, num livro famoso intitulado Desafronta (história d'uma perseguição), publicado em 1895, com segunda edição em 1896.

Neste último ano parte para S. Tomé e Príncipe, pequeno arquipélago, então a jóia da colonização portuguesa, rico pela produção de café e de cacau, onde iria assistir pessoalmente à experiência colonizadora portuguesa, que criticaria em muitos dos seus aspectos, nomeadamente na exploração de que eram vítimas não só os pretos, normalmente idos de Angola, onde não mais regressavam, mas também alguns brancos sem fortuna, que aí morriam na maior pobreza e sem auxílio do governo. De resto, teria sido esse o destino de um seu irmão, Joaquim António, que aí falecera pouco tempo antes da sua chegada a S. Tomé. A estadia na ilha, situada na linha do Equador, ficará marcada pela sua actividade clínica - "médico de brancos e de pretos" - pelo contacto com outro irmão, Francisco António de Almeida, juiz da Relação em Angola, cuja acção se estendia igualmente ao arquipélago, onde acabou por comprar uma roça, propriedade da família até há bem pouco tempo, pelas críticas à organização hospitalar oficial, pela defesa dos interesses dos colonos desprotegidos com a organização da associação Pró Pátria e de um hospital, pela defesa do progresso da ilha e pela colaboração dada aos jornais da metrópole, nomeadamente ao jornal republicano de Coimbra Resistência.

Em Julho de 2003 regressa ao continente europeu, onde vai reiniciar a sua militância republicana, não antes de realizar uma viagem científica e cultural pela França, Suíça e Itália. Mas, mesmo de Paris, onde esteve num hospital 
a actualizar-se no domínio das "doenças dos países quentes", em que virá a exercer clínica particular em Lisboa, continuará a enviar artigos políticos, nomeadamente o que seria publicado no jornal O Mundo (21 de Novembro de 1903) sobre o "Partido Republicano".

Em Lisboa vai ocupar um lugar cada vez mais importante entre os republicanos, continuando a sua carreira de orador (iniciada em Coimbra), que o tornaria particularmente conhecido, em 24 de Janeiro de 1905, durante as exéquias fúnebres de Rafael Bordalo Pinheiro, o nosso grande caricaturista. Membro do Partido Republicano, maçon e com ligações à carbonária, vai participar activamente na luta contra a Monarquia em crise, como jornalista (nas vésperas da "Revolução Republicana" de 5 de Outubro de 1910, será inclusivamente director e redactor principal da revista Alma Nacional), como deputado do minoritário mas activíssimo partido, a partir de Agosto de 1906 até Maio de 1907, como orador em celebrados comícios, como revolucionário não só em luta contra a "ditadura" de João Franco, mas sobretudo contra a Monarquia.

Implantado o novo regime - repúblicas, para além das da América, incluindo o Brasil, em 1910 e na Europa, havia apenas a República Francesa e a tradicional Confederação Helvética - , António José de Almeida será Ministro do Reino, a pasta de maior projecção, que abarcará áreas tão diversas como a saúde, o trabalho, a instrução pública e a ciência, a administração interna. Começam então as clivagens e as aclamações e movimentações de rua. António José tanto será saudado pelas suas reformas, como o descanso semanal e as regalias concedidas aos professores, em especial do ensino primário, como começará a ser contestado pelas suas reformas políticas eleitorais. E, depois da sua experiência governamental, conhecerá grandes vaias populares pela sua luta em prol da tolerância em relação a monárquicos e católicos, opondo-se, sempre que pôde e como pôde, à política anticlerical extremista de Afonso Costa, seu companheiro de luta e seu rival e adversário nas "guerras da República", autor da célebre lei de separação do Estado das Igrejas (20 de Abril de 1911), que António José assinou como membro do Governo Provisório (1910-1911), mas de que discordou, sobretudo no que diz respeito à sua aplicação prática.

No ano de 1911, aproveitando a sua experiência jornalística, lança um novo jornal, República (15 de Janeiro), que se tornará o órgão do Partido Evolucionista, saído em 1912 do Partido Republicano Português (PRP), o qual continuará a 
identificar-se com a via dos chamados "democráticos", de Afonso Costa. Estarão quase sempre em desacordo, só se voltando a encontrar em momentos adversos, como sucedeu durante o governo de pacificação organizado durante a Primeira Guerra Mundial, conhecido, à semelhança da França, com o Governo da "União Sagrada" (15 de Março de 1916 - 25 de Abril de 1917), em que António José será o Presidente do ministério e Afonso Costa Ministro da Justiça, substituindo-o interinamente durante um mês, ou durante a ditadura de Sidónio Pais (Dezembro de 1917 - Dezembro de 1918), em que António José manifestou a sua solidariedade ao político democrático, preso em Elvas.

Mas, Afonso Costa vai em breve abandonar a vida partidária activa, deslocando-se para Paris, onde vai participar nas conferências internacionais que puseram termo à guerra e na recém-criada Sociedade das Nações. O mesmo vai suceder no outro grande partido da trilogia partidária republicana, o Partido Unionista, de Brito Camacho, cujo líder seguirá para Moçambique como Alto Comissário, e com o Partido Evolucionista, pois António José de Almeida será eleito Presidente da República (6 de Agosto de 1919), em que permanece, sendo o único a cumprir um mandato completo de quatro anos, até 5 de Outubro de 1923. Será, todavia, um mandato difícil, marcado pela proliferação de partidos efémeros e pela situação de instabilidade e violência, sobretudo em Outubro de 1921, com o golpe mais sangrento ocorrido durante a Primeira República depois da morte do Presidente Sidónio Pais (14 de Dezembro de 1917), que levou ao assassinato do Presidente do Governo António Granjo e de algumas figuras significativas, como Machado Santos, considerado oficialmente o "herói" da revolução republicana de Outubro de 1910, e Carlos da Maia. Mas, ao mesmo tempo verificar-se-ão as últimas tentativas de conciliação, nomeadamente com a Santa Sé, a épica viagem aérea de Sacadura Cabral e Gago Coutinho ao Brasil e a primeira viagem de um chefe de Estado português ao país irmão, independente desde 1822. Regressa a popularidade de António José de Almeida e volta a verificar-se os seus discursos arrebatados com banhos de multidão, como sucedera durante os comícios republicanos.

Depois de 1923 verificam-se os últimos anos e os derradeiros momentos de António José de Almeida, que, atacado de gota, percorreu durante toda a sua vida as termas portuguesas e estrangeiras à procura de uma panaceia que o curasse. Morre em 31 de Outubro de 1929, já a Primeira República dera lugar 
à Ditadura Militar, surgida da chamada "Revolução Nacional", de 28 de Maio de 1926. Mas, a sua popularidade permanecerá após a morte, com elogios de todas as facções, o que possibilitará que seja homenageado com uma estátua em Lisboa, inaugurada em 31 de Outubro de 1937, em pleno Estado Novo de Oliveira Salazar. Mesmo o ditador não ficara insensível a um político que foi e será considerado um "homem bom" e "honesto", o que se casava, de resto, com a imagem que se formava a seu respeito. O célebre escritor Fernando Pessoa dirá que ele representou a parte que "mais se integrou no sentimento nacional português", a parte "mais sã, a mais patriótica" do republicanismo67, e António Ferro, que dirigirá a Propaganda do Salazarismo, dizia que "a República entrou na alma do povo [...] pela voz de António José de Almeida” e a ele se devia a força do republicanismo em Portugal ${ }^{678}$. Por isso, a toponímia do país reflectiu essa popularidade e esse populismo, havendo em Portugal, continental ou insular, assim como houve nas colónias muitas ruas e praças com o seu nome.

\section{A cultura política de António José de Almeida}

Um militante político deste tipo não se pode caracterizar, como é evidente, como um intelectual. António José de Almeida não foi propriamente um teórico político, mas um prático, um "tribuno popular", como gostava de se identificar. Por isso não encontramos no seu espólio uma grande biblioteca, como sucede, por exemplo, na casa de um político da aristocracia terratenente como foi José Relvas. Apesar de - como se aludiu e como o próprio quis afirmar-se - ser "filho do povo", não era propriamente um proletário, pois o seu pai era um pequeno proprietário agrícola e (por assim dizer) "letrado", com influência política no concelho de Penacova, como membro do Partido Progressista, chegando a Presidente da Câmara. Mas também porque o era, identificando-se com o meio rural e popular, não se destacaria como ideólogo de grande solidez de ideias.

677 "Para a obra 'Considerações pós-revolucionárias'. 1910/1911-1912”. In Fernando Pessoa, Páginas de pensamento político - 1. Org., introduções e notas de António Quadros. Lisboa: Publicações Europa-América, 1986, pp. 50-51.

${ }^{678}$ Diário de Notícias, 2.11.1929. 
Claro que a cultura de António José de Almeida, como a de todo o republicano português, passaria pela leitura, mais ou menos profunda ou apressada, do positivismo de Comte e de Littré e do conhecimento, que neste caso lhe vinha da sua formação de médico, de Darwin. Todavia, o que lhe suscitava maior interesse, eram as concepções políticas de Gambetta, cuja obra lhe veio a ser deixada em testamento por Manuel de Arriaga, o primeiro Presidente da República eleito, seu protector e amigo. De resto, a sua posição ao mesmo tempo radical, quando Gambetta atacou o Império, e conciliadora, quando político e governante da República Francesa, foi, de algum modo, seguida pela posição de António José, de crítica entusiasmada à Monarquia e de tolerante conciliação com os adversários colocados mais à direita durante a República.

Sentimental e arrebatado, os seus modelos foram, efectivamente, as grandes figuras da prática republicana e social e os seus grandes rasgos literários e heróicos, sobretudo quando morriam ou sofriam pela causa. Quando, ainda estudante, discursava, em 15 de Janeiro de 1893, junto da sepultura do professor de Matemática José Falcão, um símbolo nos meios universitários, irmanava o seu mestre do republicanismo (e mestre da sua geração) com "o entusiasmo de Hugo", o escritor de Os Miseráveis, "o estoicismo de Baudin", morto nas barricadas de Paris em 1851, e "essa força resignada, ora brusca ora terna, semelhante a Kossuth", o herói nacional da Hungria, que lutou pela sua independência, mas que, perante a força dos exércitos russos, teve de se exilar na Turquia e depois na Itália ${ }^{679}$.

Herculano, o escritor mas igualmente o símbolo moral da Pátria, constituiu também o seu ideal: "um grande homem", "a síntese de uma geração de rebeldes", que o povo, intuitivamente, sem o ler, tornou "uma figura familiar e amada", porque representava a "incorruptibilidade no meio de um mar de podridão"680. Rafael Bordalo Pinheiro, que elogiou como se disse em discurso fúnebre, não era apenas o excelente desenhador, mas sobretudo o artista de intenção social. Por isso, não se deve admirar que, comparando-o com Rodin, tenha eleito o caricaturista, inventor do "Zé Povinho", símbolo do povo português, explorado

${ }^{679}$ Discurso proferido à beira do túmulo do Doutor José Falcão, no cemitério de Santo António dos Olivais (Coimbra), em 15 de Janeiro de 1903. Transcrito in Quarenta anos de vida literária e política, Lisboa: J. Rodrigues e C. ${ }^{a}$, vol. I, p. 56-58

680 "Centenários", Alma Nacional, 28.4.1910. 
por todas as oligarquias do poder ${ }^{681}$. Eça de Queirós, por sua vez, aparece-lhe sobretudo como "um demolidor formidável, que pela análise, pela ironia e pelo sarcasmo abalou o edifício monárquico", como um escritor que deixou "uma obra de moral" que jamais poderia ser entendida como antinacional ${ }^{62}$. E Guerra Junqueiro, poeta ora combativo, de A Velhice do Padre Eterno e de Finis Patriae, ora místico, de Os Simples, será sempre, até ao fim da vida, em 1923, o seu exemplo e o exemplo "oficializado" pelos republicanos. É, pois, nesse sentido prático e literário, social e moral, que sobretudo vê a cultura e nunca numa concepção teórica, de construção de um pensamento político original, ou puramente estética.

Do mesmo modo, os seus escritores de eleição fora das fronteiras serão Victor Hugo, como se disse, e Zola e serão consideradas "obras primas" os seus romances realistas, bem como os de Alphonse Daudet (O Nababo) ou do escritor republicano espanhol Vicente Blasco Ibañez (Catedral).

\section{António José de Almeida e a Itália}

Neste contexto, não é de admirar que António José fosse à Itália e à França buscar o verniz cultural que lhe faltava. De resto, essas peregrinações pela Europa e pela "cultura europeia" constituíam a rota dos portugueses, acantonados na ponta ocidental da Península Ibérica, que, todavia, por vezes, espíritos mais lúcidos criticavam, em busca de uma verdadeira cultura nacional. Assim, logo chegado de S. Tomé, não deixou, como se disse, de fazer a viagem cultural por "essa Europa", que prolongou ao longo da sua vida, em curtas estadias termais, em Vichy ou em Baden Baden.

Assim, ficou impressionado com a "luminosa Itália da arte" e de Garibaldi, encontrando, por sua vez, em Paris não apenas o aperfeiçoamento dos seus conhecimentos médicos, mas também a força sempre presente da Revolução, que o levou a tocar o clarim republicano à sombra da estátua de Danton ${ }^{683}$.

\footnotetext{
${ }^{681}$ Discurso proferido no funeral de Rafael Bordalo Pinheiro, em 24 de Janeiro de 1905, no cemitério dos Prazeres, in Quarenta anos de vida literária e política, op. cit., vol. I, pp. 91-97.

${ }^{682}$ República, 29.1.1915.

683 "Partido Republicano", O Mundo, 21.11.1903, e Resistência, 26.11.1903
} 
Quanto à Itália, falou dela com entusiasmo por altura da vinda a Lisboa da famosa actriz Italia Vitaliani (1866-1938), uma das prime donne do teatro, cujas representações viu na sala do D. Maria II. Mas, mesmo no seu elogio, não deixou de vir ao de cima a sua apetência pela arte social em que, como nas artes plásticas, conforme dizia (aludia então a Meunier, que morrera nesse ano em Bruxelas, autor de estátuas como "Le Débardeur du Port d'Anvers" ou "Le Marteleur"), se tornava também a arte cénica. Assim, nesse texto, publicado no jornal Resistência, de Coimbra, em 25 de Junho de $1905^{684}$, louva arrebatadamente as suas representações de Maria Antonieta, de Magda, de Fedora ou de Zázá, mas lamenta não a ter podido ver "nalguma peça de grande vulto em que o seu génio pudesse crispar-se à máxima tensão da sua força”. Ou seja, lamenta não a ter visto representar, por exemplo, esses "dois actos ligeiros, mas desajeitadamente verdadeiros das Almas Doentes, peça que há pouco se viu em D. Maria e que é uma estranha e impetuosa manifestação de talento"685. Tratava-se da peça de Marcelino Mesquita, integrada numa concepção ultra-romântica e social do teatro português.

Mas, é, como se disse, a propósito de Itália Vitaliani que António José fala da Itália, que visitara pouco tempo antes. E fá-lo no seu sentir sempre arrebatado e ao mesmo tempo um pouco ligeiro e ingénuo de ver a cultura e a vida, que constituía, aliás confessadamente, a sua maneira de ser. Vejamos as suas próprias palavras:

"Eu amo e adoro essa Itália donde ela nos veio. A Itália da arte, a Itália do sonho, que vive na sua quimera astral e relumbrante. Amo especialmente a velha Turim onde Vitaliani nasceu. Nessa terra de vago romantismo e sóbria austeridade, encontrei alguns dos maiores encantos da minha vida. Não sou artista, sou um pobre médico de pretos que segue as coisas da arte por instinto, mas que nem por isso deixa de olhar com olhos enlevados para as eternas maravilhas dessa arte. O coração dos homens precisa de amar e felizes de nós quando temos alguma linda mulher que recebe nos seus olhos negros a nossa imagem e no nosso coração apaixonado a recordação do nosso amor. Felizes de nós que, soberbos, perante nós próprios, do delírio

\footnotetext{
684 "Italia Vitaliani", Resistência, 25.6.1905. Ver também em Quarenta anos de vida literária e política, Vol. I, pp. 99-109

${ }^{685}$ Cfr. ob. e vol. cits., pp. 104-105
} 
desse amor, arvoramos essa mulher na estrela guiadora da nossa vida.

Mas o coração humano já dá, nesta hora da civilização, para muito mais. Sem ofensa para a nossa mulher ou para a nossa noiva, amamos, embora com amor diverso, o nosso ideal político a que votamos o nosso sangue, e a arte serena e inviolável para que sobe o nosso eterno anseio.

Pois é bem a arte italiana que eu amo de preferência. E nessa casta a pacata Turim ela ressalta de toda a parte como se fosse uma florescência de pedra e uma flora nova só vista naquele solo lendário. Desde Superga, onde há maravilhas inigualáveis, até à estátua de Garibaldi, que se ergue impávida no seu cerro selvagem, em cada rua, em cada casa, em cada canto, borbulha a arte como borbulha à flor da terra a água que referve no sub-solo.

\section{[...]}

A Itália desborda de comunicabilidade e de fraternidade. Ela mandanos o seu exemplo e o seu incentivo por mil vias diferentes: pelas telas dos seus pintores, pelas obras dos seus homens de letras, pelos mármores dos seus escultores, pelos discursos dos seus oradores, pelas descobertas da sua ciência, pelos triunfos de algumas das suas indústrias, pelas suas magníficas revoltas armadas de que Milão é um exemplo e pelos seus actores de que Vitaliani é um glorioso representante. No mostruário imenso das aptidões da sua raça, que a Itália espalha pelo mundo, Vitaliani é das jóias de maior valor.

Saudá-la a ela é saudar toda a Itália e sobretudo a luminosa Itália da arte’686.

Este texto parece-nos bem demonstrativo da cultura de António José de Almeida e, afinal, da cultura de muitos dos militantes republicanos do seu tempo. Trata-se mais de uma cultura de superfície que se surpreende perante o que vê, do que de uma cultura teórica que analisa e aprofunda os conceitos, é mais uma cultura de sensibilidade do que de razão, num tempo de afirmado racionalismo, mas em que o sentimento, a paixão, ou a intuição, começam a suplantar a pura lógica positivista e cientista.

\footnotetext{
${ }^{686}$ In Quarenta anos de vida literária e política, Vol. I, pp. . 107-109.
} 


\section{A terminar...}

Importa analisar esta passagem de uma cultura positivista a uma cultura intuicionista para percebermos a lógica dos movimentos intelectuais e políticos das "novas gerações", que veio a desembocar em concepções patrióticas e nacionalistas, e por vezes em sentimentos bélicos e autoritaristas, como sucedeu na Itália, na Alemanha e... em Portugal. António José de Almeida manteve-se coerentemente um republicano e o mesmo sucedeu, por exemplo, a um intelectual da "nova geração" ${ }^{687}$, Alberto Veiga Simões, que com ele comungou as ideias republicanas evolucionistas, até que dele se afastou para entrar numa via "radical", na busca de um republicanismo originário, o qual nos apresentou um panorama cultural muito mais rico, cheio de alusões aos grandes vultos de uma "certa cultura de época", como Goethe, Wagner, Nietzsche, Bergson, D’Annunzio... Mas, outros, como Alfredo Pimenta, também seu companheiro de luta até 1914, que se tornou o principal redactor do jornal República, há-de tornar-se um monárquico integralista e, muito mais, um defensor do autoritarismo e do germanismo, mesmo quando Hitler tomou o poder.

Apesar de António José de Almeida ter sido dos mais arrebatados críticos da Monarquia e do seu Rei, nomeadamente D. Carlos, vítima de um assassinato político, em que não participou, mas que até certo ponto justificou, não deixou - como dissemos — de ser respeitado pelos seus adversários. Intelectuais modernistas, influenciados ou mesmo atraídos por D’Annunzio, como António Ferro e Fernando Pessoa, vieram a considerá-lo uma das poucas personalidades que admiravam na Primeira República. E, como vimos também, mesmo no tempo da Ditadura Militar e do Estado Novo, pôde ser homenageado e celebrado por republicanos, de direita ou de esquerda. Ele poderia ser entendido, abusivamente é certo, como uma espécie de "alma nacional" e "republicana" que existiria para além de todos os credos e de todos os partidos.

A Itália dera precocemente a volta institucional para o fascismo, apesar de algumas das suas figuras históricas, representativas da liberdade e das utopias

${ }^{687}$ Cfr. A Nova Geração. Estudo sobre as tendencias actuaes da litteratura portaguesa. Coimbra: França Amado, 1911. Ver, da nossa autoria, "Caminhos da cultura portuguesa do 'fim de século'. Rumos contraditórios das "novas gerações". In Los 98 ibéricos y el mar. Actas. Tomo II: La cultura en la Península Ibérica. Madrid: Sociedad Estatal Lisboa’98, 1998, pp. 121-135. 
sociais, como Garibaldi ou Mazzini, tivessem sido aproveitadas pela lógica do Stato nuovo. O Integralismo Lusitano, o nosso movimento monárquico correspondente à Action Française, tembém fizera isso com figuras como Herculano, Garrett, Antero ou Teófilo. O nosso regime autoritário de "Estado Novo" poderia fazer algo de idêntico com António José de Almeida, nem que fosse pelo silêncio... 